\title{
Consenso, racionalidad y legitimidad
}

\author{
ERNESTO GARZÓN VALDÉS \\ Universidad de Maguncia, RFA
}

En la filosofía política contemporánea, hay dos conceptos que juegan un papel esencial para el tratamiento del problema de la legitimidad del Estado: el de consenso y el de racionalidad. Sin embargo, la importancia que generalmente se concede a estos conceptos no significa que exista acuerdo acerca del contenido semántico de racionalidad y acerca de las situaciones en que ha de practicarse el consenso racional, que es el que se supone permite juzgar acerca de la legitimidad del orden esta- tal. En lo que sigue me propongo (I) recordar brevemente, y a guisa de ejemplo, posiciones que toman como marco del consenso alguna de las dos situaciones mutuamente excluyentes $y$ conjuntamente exhaustivas: la situación fáctica o la hipotética; (II) exponer el concepto de racionalidad que ellas sustentan y (III) sugerir un concepto de legitimidad en el que el consenso y la racionalidad juegan un papel diferente del que suele atribuírseles.

Entre las teorías que adoptan como marco para el análisis de la legitimidad la situación fáctica de los miembros de una determinada sociedad pueden mencionarse, entre otras, la de Niklas Luhmann, la de Jürgen Habermas y la de James S. Fishkin.

Como es sabido, según Luhmann, cada sistema político instituye, a través de un procedimiento específico para la adopción de sus normas y decisiones, sus propios fundamentos de legitimidad o legitimación (ambos términos son utilizados indistintamente por este autor). La aceptación rutinaria de los resultados obtenidos por el procedimiento es condición necesaria y suficiente para la legitimidad del sistema. Cuáles sean las razones por las cuales los miembros de un sistema político aceptan las decisiones es irrelevante. Se podría hablar en este sentido de motivaciones «en bruto». Lo importante es que exista un consenso básico de aceptación del procedimiento. Con palabras de Luhmann:

El sistema político tiene que poder combinar motivaciones incompatibles del más diverso tipo e igualarlas de manera tal que se produzca casi una aceptación no motivada, evidente, de las decisiones obligatorias [1975, 159], 
o

[L]a incuestionabilidad de la validez legítima de las decisiones obligatorias es una de las características típicas del sistema político moderno, como una especie de consenso básico, que puede ser logrado sin que exista acuerdo acerca de lo que es objetivamente correcto en el caso particular, y que estabiliza el sistema $[1975,29 \mathrm{ss}$.$] .$

La tesis de Luhmann del consenso fáctico, con independencia de la génesis de las motivaciones que conducen al mismo, deja expuesta su teoría de la legitimidad a fuertes objeciones que no he de entrar a analizar aquí. Quiero tan sólo mencionar dos de ellas: la del positivismo ideológico y la de la indoctrinación o manipulación. El positivismo ideológico permite justificar autorreferencialmente cualquier sistema político. La afirmación de la existencia misma de un sistema político equivaldría a un juicio de legitimidad. Y como no importa la génesis de las motivaciones del consenso, no está excluida la posibilidad de la manipulación de quienes deben prestarlo, es decir, no está excluida la posibilidad de un paternalismo extremo que mantenga a los ciudadanos en situación de infantilismo cívico. Ninguna de estas dos consecuencias es muy atrayente cuando se quiere disponer de un criterio de legitimidad que no se limite a estipular las condiciones necesarias y suficientes para la existencia de un sistema político.

Jürgen Habermas parte igualmente de la situación del consenso fáctico. Quienes participan en el discurso comunicativo son los miembros de la sociedad que son quienes juzgan acerca de hasta qué punto las estructuras políticas y sociales existentes deben ser mantenidas y reconocidas:

[L]a imposición duradera de una norma depende también de que en un contexto dado [...] puedan movilizarse razones suficientes para que en el círculo de sus destinatarios su pretensión de validez pueda presentarse, al menos, como justificada. Aplicado a las sociedades modemas esto significa: $s i n$ legitimidad ninguna lealtad de las masas [1983, 72].

Pero, a diferencia de Luhmann, Habermas enmarca este consenso fáctico con condiciones trascendentales a fin de asegurar una situación ideal de discurso. Es esta referencia a una situación ideal lo que permite una lectura doble de Habermas: la de la situación fáctica y la de la hipotética.

Quizá lo relevante en el contexto de este análisis es señalar que la referencia a las condiciones trascendentales en Habermas permite también «filtrar» las motivaciones y eliminar de esta manera el peligro de la manipulación paternalista. 
Sin embargo, quedan pendientes no pocas cuestiones vinculadas con el carácter ambiguo de la situación en la que ha de lograrse el consenso: si se trata de una situación fáctica, no hay duda que el tiempo juega un papel fundamental, como así también el nivel de información y de interés de los participantes en llegar a una solución que tome en cuenta exclusivamente el bien común. Si se parte de una situación fáctica, ¿cómo puede pasarse de la voluntad de todos (mero consenso fáctico) a la voluntad general (consenso bajo condiciones trascendentales hipotéticas)?

Y queda también pendiente la cuestión de saber cómo ha de lograrse en una situación fáctica la vigencia efectiva de las condiciones del discurso ideal habermasiano. A través de la discusión racional, ello parece más que problemático en virtud de la experiencia histórica, que permite inferir una probabilidad muy reducida de renuncias voluntarias a privilegios que contradicen la situación de igualdad presupuesta en el discurso de comunicación ideal. ¿Estarían entonces autorizadas formas de acción colectiva no consensuales para la obtención de esta situación ideal de discurso? ¿O se trata más bien, en el caso de esta última, de una situación hipotética que proporcionaría criterios de evaluación acerca de la justicia o injusticia de una situación fáctica? Si se acepta esta segunda sugerencia, entonces la teoría de Habermas tendría que ser catalogada entre las que proponen un consenso hipotético y a las que he de referirme un poco más adelante.

Una tercera ilustración de la adopción de un punto de partida fáctico, pero con motivaciones "filtradas", es la ofrecida por James S. Fishkin (1988) con su noción de «cultura política autorreflexiva»:

La premisa de mi argumento constructivo es que las justificaciones de la autoridad del Estado tienen que estar dirigidas a aquéllos que tienen que vivir bajo tal autoridad, a aquéllos que tienen que vivir con la pretensión, habitualmente respaldada con un enorme poder, de que los innumerables efectos negativos del Estado en nuestras vidas cotidianas están plenamente justificados. La primera cuestión que hay que plantear acerca del Estado no es si hemos "consentido" a él en algún sentido (tácito, expreso, hipotético o de algún otro tipo). Más bien de lo que se trata es si el Estado nos ha permitido estar en una situación en la que nos es posible, en alguna manera razonable, evaluarlo [... La primera cuestión de la filosofía política es si la forma de cultura politica que es tolerada o propiciada en un Estado dado es una que permite a quienes están sujetos a su autoridad evaluarla, determinar desde adentro, si la autoridad a la que ellos están sometidos es justificable $[1988,61]$.

Según Fishkin, la evaluación acerca de si la autoridad es o no justificable se lleva a cabo de acuerdo con los argumentos que es racional aceptar dentro de la respectiva cultura política. Es la posibilidad de la 
autorreflexión la que permitiría evitar los peligros de la indoctrinación. Todo Estado que niegue a sus súbditos las condiciones necesarias para una «razonable evaluación de su propia autoridad [...] sin que importen cuáles sean sus otros beneficios, se negaría a sí mismo la posibilidad de resolver el problema de la legitimidad» (1988, 62 ss.). Según Fishkin, lo decisivo es la existencia de las condiciones de evaluación, sin que importen los resultados de la misma.

Esta posición tiene aparentemente la ventaja de que elimina toda posibilidad de manipulación o de paternalismo. Es obvio que ésta es una buena vía para evitar la dictadura. La cuestión es saber si con ello se ha asegurado también la legitimidad del respectivo sistema político. Me inclino a creer que tal no es el caso.

En efecto, ¿podría sostenerse, por ejemplo, que un sistema político que satisface las conclusiones a las que llega la población con respecto a la conveniencia de practicar la antropofagia aplicada a las mujeres, cuando su número supera ampliamente el de los hombres (esta población es estrictamente monogámica), ha solucionado cabalmente el problema de su legitimidad? Puede suponerse, para completar las condiciones de Fishkin, que el gobierno otorga a la población todas las posibilidades de autorreflexión y de información acerca de lo que sucede en otras sociedades en donde la antropofagia está estrictamente prohibida (no sólo con relación a las mujeres); el resultado es siempre el mismo: la población sigue propiciando en su inmensa mayoría (gracias al voto de las mujeres casadas autorreflexivas y de las solteras que prefieren correr el riesgo del asador al de la infidelidad del posible marido, provocada por un exceso de solteras) la antropofagia femenina. Supongamos ahora que sube al poder un nuevo rey, Filógeno I quien, tras largas meditaciones, llega a la conclusión de que no hay ningún argumento racional que permita la antropofagia femenina y por ello resuelve prohibirla. Además, para evitar que incorregibles amantes de la carne femenina (bajo la inaceptable forma de la antropofagia, claro está) intenten mantener viva una tradición éticamente reprochable, prohíbe también que se hable más del asunto, es decir, actúa dictatorialmente en este tema y comete el supuesto pecado de indoctrinación paternalista. ¿Diríamos en este caso que el sistema ha perdido legitimidad porque ya no cuenta con el consentimiento fáctico y autorreflexivo vigente en la cultura política de su sociedad?

El consentimiento fáctico es, sin duda, la expresión más confiable de los valores vigentes en una determinada sociedad. De él se infiere el contenido de la moral positiva de aquélla, es decir, si se quiere utilizar una expresión de H.L.A. Hart: el punto de vista intemo de los miembros de una sociedad con respecto a las normas que deben regirla. Pero este punto de vista interno es insuficiente para juzgar acerca de la legitimi- 
dad, si es que ella ha de ser entendida como coincidencia de los principios y reglas vigentes en una sociedad política con los principios y reglas no ya de una moral positiva sino de una moral esclarecida o ética.

En vista de los problemas que plantea el consenso fáctico, podría pensarse que la salida está en buscar una situación ya no real sino hipotética.

También aquí quiero mencionar brevemente tres posiciones haciendo referencia, al igual que en el caso del consenso fáctico, al tipo de motivaciones que ellas aceptan.

James Buchanan ha propuesto un modelo de justificación del Estado sobre la base de un consenso racional e hipotético sujeto tan sólo al respeto de la individualidad de cada cual. Esta individualidad está definida por el marco de los derechos de cada cual en una situación de "distribución natural» a la que se llega invirtiendo esfuerzos del más diverso tipo (fuerza física, astucia, inteligencia, engaño). No obstante el heterogéneo origen de esta distribución natural, los individuos encontrarán racional, según Buchanan, aceptar consensualmente un contrato constitucional que evite los gastos improductivos de ataque y defensa:

Cualesquiera que puedan ser las características de esta distribución, sea que prevalezca una simetria aproximada o que uno de los participantes se convierta en un gigante del consumo y el otro en un pigmeo [...] ambas partes estarán mejor si se logra llegar a un acuerdo [1975, 24 s.].

Como esta situación de distribución natural es compatible con las mayores desigualdades, puede suceder, desde luego, que sea conveniente para las partes contratantes firmar un contrato de esclavitud:

La eliminación completa de otras personas puede no ser, sin embargo, el curso de acción preferido por quienes poseen capacidades superiores. Un estado más preferido aún puede ser aquél en el cual a quienes son «débiles» se les permite que realicen esfuerzos para producir bienes, de los cuales después los "fuertes» se apoderan [...] para su propio uso. En esta situación, el contrato de desarme que es negociado puede ser similar a un contrato de esclavitud en el cual el "débil» produce bienes para el "fuerte» a cambio de conservar algo más que la mera subsistencia, que puede ser incapaz de asegurar en la situación de anarquía. Un contrato de esclavitud, al igual que los otros contratos, define derechos individuales $\mathrm{y}$, en la medida en que esta asignación es mutuamente aceptada, pueden asegurarse ganancias mụtuas de la reducción consiguiente de los esfuerzos de defensa y depredación $[1975,59$ s.].

Este contrato de esclavitud celebrado en la situación hipotética de «distribución natural» sería además «bueno», y por lo tanto legítimo, ya que una situación es juzgada "buena» en la medida en que permite que 
los individuos obtengan lo que desean, cualquiera cosa que ello sea, con la única condición del acuerdo mutuo $(1975,2)$.

Parece difícil aceptar esta fundamentación racional y consensual del Estado originado en una situación hipotética en la que el mero consenso es fuente de legitimidad sin ninguna otra limitación normativa que la del respeto a la individualidad plasmada a través de la distribución natural.

Un paso hacia la imposición de limitaciones normativas más fuertes en la situación hipotética de consenso es el propuesto por David Gauthier (1986). La limitación está dada en este caso por la cláusula cautelar de Locke, que prohíbe beneficiarse infligiendo un daño a otro. Esta cláusula es la que impide considerar como equitativo un contrato hipotético entre amos y esclavos. A diferencia de lo que sucede en Buchanan, para que sea racional aceptar una negociación, hay que eliminar las situaciones en la que una de las partes impone a la otra una coerción:

Argumentaremos que si el resultado no cooperativo implica coerción, entonces ésta tiene que ser reducida eliminando los efectos de esta coerción si es que ha de servir como posición inicial para negociar una estrategia conjunta que racionalmente exija el cumplimiento individual [1986, 192].

La cláusula cautelar de Locke prohíbe la violación de deberes negativos pero no impone deberes positivos. La coacción a la que se refiere Gauthier es aquélla que resulta del incumplimiento de aquéllos y no de estos últimos. En el caso de la propuesta de Gauthier, tampoco es relevante el origen de las motivaciones; lo único que importa es que las preferencias sean considered pero, como señala Fishkin $(1988,54)$, este criterio no especifica nada acerca de las condiciones apropiadas para la formación de las preferencias y, por lo tanto, éstas no están libres del peligro de la manipulación. Según Gauthier:

Las preferencias son considered si y sólo si no hay conflicto entre sus dimensiones de comportamiento y actitud, y son estables bajo la experiencia y la reflexión [1986, 33].

La posición de Gauthier, al limitar la exigencia de "consideración» de las preferencias a la coherencia entre comportamiento y actitud, no excluye el problema de la indoctrinación o de un perverso paternalismo. Ouienes en la sociedad medieval denunciaban a ciertas personas como brujas (de acuerdo con concepciones religiosas firmemente enraizadas) no presentaban ningún conflicto entre actitud y comportamiento (a menos que tuvieran ciertas dudas acerca de la firmeza de sus convicciones, como el célebre Dr. Sebastian Röttinger [1537-1608], abogado del Consejo Municipal de Nördlingen quien, por una parte, con sus informes «jurí- 
dicos" colaboró eficazmente en la quema de brujas [35, según las crónicas municipales] y, por otra, en su testamento legó 3.000 onzas de oro para becas «a fin de reconciliarse con la posteridad»); pero sería difícil inferir de ello una evaluación moral positiva de su comportamiento.

La teoría de John Rawls (1971) es un buen ejemplo de un intento de propuesta de una situación hipotética como punto de partida para un consentimiento racional por parte de individuos cuyas motivaciones han sido "filtradas" a través del recurso del "velo de la ignorancia». En este caso no se dan ya problemas de indoctrinación pero sí los que Fishkin llama «institucionales»:

La dificultad es que una vez que nos apartamos de la vida real, podemos apelar a cualquier número de situaciones contrafácticas. Aun la menor diferencia por lo que respecta a la imparcialidad y la menor diferencia en las nociones de pretensiones o intereses relevantes en estas situaciones imaginarias conducen a resultados drásticamente diferentes [1988, 58].

Y cabe desde luego preguntarse si la propuesta de un consenso entre los futuros miembros de una sociedad en una situación hipotética no constituye, como diría Hare, una dramatización inútil que no añade sustancialmente nada al recurso clásico del observador imparcial. Ninguna de las seis posibilidades de justificación de un sistema político como legítimo resulta ser satisfactoria. Antes de formular una propuesta al respecto y como paso previo, pienso que conviene analizar, aunque más no sea brevemente, el tipo de racionalidad que presuponen las teorías mencionadas.

\section{II}

La teoría de Luhmann parece casi prescindir del elemento racionalidad. Su criterio de aceptación rutinaria vuelve irrelevante hasta un concepto de racionalidad en sentido débil, es decir, aquel que, si bien es cierto prescinde de la génesis de las preferencias y creencias, requiere al menos coherencia entre aquéllas y las acciones.

Este sentido débil de racionalidad está presente en la concepción de Buchanan. Aquí se presupone que las preferencias de la gente son completas, transitivas y continuas - lo que permite representarlas en una función de utilidad-y, además, egoístas. En el modelo de Buchanan, las personas se comportan no sólo como seres racionales en sentido débil sino también como actores económicos. A través de acciones racionales y egoístas, la gente crea un resultado que se supone es bueno para todos, en el sentido de que todos lo consideran como tal, dadas sus preferencias y las circunstancias de la situación fáctica en que se encuen- 
tran; por ello, hay que calificar de "bueno» al contrato que celebran los unos para salvar su vida y los otros para adquirir esclavos.

También Gauthier acepta un concepto de racionalidad débil, con el agregado de la motivación egoísta de maximización de las propias utilidades. Pero, además, supone que cada persona posee una información completa acerca de las posibles preferencias y elecciones de los demás. La racionalidad que le interesa a Gauthier es justamente la racionalidad estratégica. Como esta última está directamente vinculada con los comportamientos esperables de los demás, es obvio que, según las circunstancias, el contenido de qué sea lo razonable hacer puede también variar. Las preferencias son racionales si son considered tal como se señaló más arriba, es decir, si no hay conflicto entre actitud y comportamiento. Estas preferencias expresan el valor de un estado de cosas para una persona. $\mathrm{Y}$ un estado de cosas es bueno si contribuye a su bienestar (cfr. 1986, 50). En la sociedad de los antropófagos monogámicos, la reducción culinaria del número de mujeres resulta ser «Gauthier-razonable»; si alguien se opusiera a ello, conociendo los comportamientos esperables de los miembros de esta sociedad, actuaría irracionalmente desde el punto de vista estratégico y pondría en peligro su propio bienestar (así debe haber pensado posiblemente el Dr. Röttinger cuando ejercitaba sus conocimientos jurídicos en los procesos de brujas; dado el comportamiento esperable de la mayoría de sus conciudadanos - que compartían su fervor persecutorio, pero carecían de formación "técnica" - una actuación ineficaz de su parte no habría contribuido "al honor de la villa» - como se lee en su epitafio- y mucho menos a su bienestar). Además, como nadie es culpable del resultado estadístico del superávit de mujeres y sólo rige la cláusula cautelar de Locke, no existiría ninguna obligación moral de auxiliar a las mujeres "sobrantes".

En los casos de Habermas, Rawls y Fishkin, el concepto de racionalidad parece ser tomado en un sentido fuerte. Estos tres autores hacen referencia a la elección, adquisición o modificación individualmente deliberada de los deseos e intereses. En el caso de Habermas, esta racionalidad en sentido fuerte es equiparada a la autonomía de la persona en sentido kantiano y, por ello, puede llegar a la conclusión de que la racionalidad práctica del discurso ideal conduce necesariamente a la moralidad. En lo que sigue, cuando utilice la expresión «autonomía» lo haré en el sentido de racionalidad fuerte y no con el significado kantiano de la palabra.

Mientras en la versión débil de racionalidad, la génesis de los deseos e intereses no juega ningún papel, aquí su consideración es decisiva. Es ella la que actúa como "filtro" y elimina aquellos intereses y deseos que estima "irracionales». Elster $(1983,16$ ss.) ha señalado una analogía, en mi opinión instructiva, entre deseos racionales (en el sentido fuerte) y 
creencias racionales. En ambos casos lo que interesa es la génesis causal en relación con las evidencias disponibles. Una de las consecuencias más relevantes de este concepto de autonomía es el rechazo de la adopción de deseos o intereses por inercia o porque ellos son sustentados por los demás. Por ello, la racionalidad en sentido fuerte es un arma eficaz contra la indoctrinación y contra el paternalismo injustificado.

Si la racionalidad en sentido fuerte elimina la indoctrinación y la apatía, podría avanzarse un paso más y considerar que la misma es condición necesaria y suficiente de corrección ética. Tal es la posición de Fishkin.

Desgraciadamente las cosas no son tan simples. Por lo pronto, así como en el caso de las creencias éstas pueden ser verdaderas aunque no hayan sido racionalmente adquiridas, así también puede haber intereses éticamente correctos que hayan sido impuestos heterónomamente. Ello explica, por qué existen formas éticamente justificadas de paternalismo. Más aún, «la historia de la ciencia demuestra que hay casos en los que era racional estar equivocado" (como el ejemplo de Descartes y su crítica a la creencia, racional en su época pero errónea, de que la flecha tenía una velocidad mayor en el medio que al comienzo de su trayecto; cfr. Elster, 1983, 18). Y no hay pocos ejemplos de moralistas que, con pleno uso de su autonomía, llegaron a conclusiones que difícilmente nos cuesta aceptar como éticas (basta pensar en la posición de Tomás de Aquino con respecto a la esclavitud, compartida por un gran número de sus contemporáneos). Es decir que entre consenso racional (en sentido fuerte) y corrección ética no existe una coincidencia tal que permita decir que aquél es condición necesaria y suficiente de esta última.

Lo hasta aquí expuesto parece indicar que ni el consenso (sea éste fáctico o hipotético) ni la racionalidad (en sentido débil o fuerte) de los miembros de una sociedad política ofrecen puntos de apoyo lo suficientemente seguros como para elaborar sobre ellos un concepto satisfactorio de la legitimidad. ¿Significa esto que ambos conceptos son totalmente irrelevantes para esta problemática? ¿O habrá más bien que buscar un enfoque diferente, que permita establecer una relación más fecunda entre consenso, racionalidad y legitimidad? En la respuesta a estas preguntas quiero ahora concentrarme.

\section{III}

Es obvio que los juicios de corrección ética son de naturaleza normativa y que, por lo tanto, no pueden ser inferidos sin más de juicios que describan la realidad. Pero también es innegable que las normas morales son concebidas justamente para reglar una parte de la realidad, es decir, 
el comportamiento humano y, por lo tanto, no pueden prescindir de los datos reales, ya que todo deber ser o hacer implica poder ser o hacer.

He dicho más arriba que se puede predicar la legitimidad de un sistema político cuando las normas de comportamiento en él vigentes coinciden con las de una moral esclarecida o ética. Predicar la legitimidad de un sisterna político es pues diferente a predicar la moralidad de un sujeto individual. El juicio de legitimidad es un juicio sobre la calidad de las normas; el juicio sobre la moralidad individual es un juicio sobre acciones a las que calificamos de morales cuando coinciden con normas a las que previamente hemos atribuido el predicado de morales. En el primer caso, lo que importa es la calidad de un resultado: las normas promulgadas y vigentes; en el segundo, el resultado de las acciones tiene que ser evaluado conjuntamente con la génesis de las motivaciones del actor. Por ello, en este último caso, juega un papel esencial el concepto de racionalidad fuerte. Quien tan sólo se limita a no matar o torturar por temor a la imposición de un castigo no es un buen candidato al encomio moral. En cambio, puede decirse que el país de los antropófagos adquirió legitimidad con la imposición de las nuevas leyes del rey Filógeno I, sin que importe el hecho de que sus ciudadanos cumplieran estas normas con pleno convencimiento de su bondad ética. El día que Sudáfrica derogue las leyes del «apartheid" habrá dado un buen paso en dirección de la legitimidad de su sistema; será entonces irrelevante que muchos o pocos de los actuales partidarios de la discriminación racial sigan creyendo en la fundamentabilidad moral de sus convicciones.

La legitimidad es un caso claro de la posibilidad de imposición heterónoma de conductas éticamentente aceptables. No otra cosa hace todo sistema jurídico-penal cuando castiga la violación de deberes éticos negativos (como el no matar) o positivos (como el no prestar auxilio en determinadas circunstancias). Y es esta posibilidad de imposición heterónoma de la legitimidad la que permite justificar también, en ciertos casos, el intervencionismo internacional (por ejemplo, medidas de bloqueo contra Sudáfrica). Un equivocado antropomorfismo ha tendido a equiparar los juicios de legitimidad con los de moralidad individual e identificado autonomía personal con soberanía estatal, cerrando así la vía a toda posible justificación ética de la imposición heterónoma de situaciones éticamente correctas.

Si se acepta esta interpretación, habrá que concluir que el consenso fáctico, tanto en la versión débil como en la fuerte de racionalidad, no es condición necesaria ni suficiente para la génesis de la legitimidad de un sistema político.

Pero de aquí no se infiere que el respeto de la autonomía (o racionalidad en sentido fuerte) sea un aspecto del que pueda prescindirse sin más en el concepto de legitimidad y que el consenso fáctico de ciudada- 
nos autónomos sea un dato irrelevante para la vigencia efectiva de un sistema político legítimo. Conviene precisar estas dos aseveraciones.

Por lo pronto el consenso fáctico -unánime o ampliamente mayoritario- de los miembros de un sistema político es un elemento fundamental de estabilidad. Si el sistema posee legitimidad, su aprobación por parte de los ciudadanos es obviamente relevante en grado sumo para el afianzamiento de una sociedad justa. Pero no sólo esto. Un sistema que pretenda poseer legitimidad tiene que tratar a sus ciudadanos, por lo general, como seres autónomos y sólo excepcional y transitoriamente puede aplicar medidas paternalistas como las de Filógeno I.

El deber moral de tratar como regla general (las excepciones son los casos de paternalismo éticamente justificado a los que me he referido con más detalle en otro lugar; cfr. Garzón Valdés 1987) a todos los ciudadanos como seres autónomos, capaces de formular sus planes de vida sobre la base de sus propias reflexiones, resulta de la combinación de dos premisas, una empírica y otra normativa. La primera nos dice que todos los seres humanos son básicamente iguales por lo que respecta a la posibilidad de hacer uso de la razón. La segunda, impone el deber de imparcialidad y universalidad de las normas morales que rigen la acción humana. No es necesario invocar a Descartes para aceptar la evidencia biológica de la premisa empírica. Ha sido siempre tomada en cuenta, aun por quienes han intentado justificar y otorgar legitimidad a sistemas políticos aberrantes. La estrategia de justificación no consistía en negar la igualdad esencial de los seres humanos sino justamente en afirmarla, excluyendo de la clase de los seres humanos a grupos de la población de un país o a poblaciones enteras. Tal es el caso de la tesis sustentada por Juan Ginés de Sepúlveda:

$\mathrm{Y}$ siendo esto así, bien puedes comprender [...] si es que conoces las costumbres y la naturaleza de una y otras gentes, que con perfecto derecho los españoles imperan sobre estos bárbaros del Nuevo Mundo e islas adyacentes, los cuales en prudencia, ingenio, virtud y humanidad son tan inferiores a los españoles como los niños a los adultos y las mujeres a los varones, habiendo entre ellos tanta diferencia como la que va de gentes fieras y crueles a gentes clementísimas, de los prodigiosamente intemperantes a los continentes y templados, y estoy por decir que de monos a hombres $[1941,101]$.

En el siglo $\mathrm{XX}$, la barbarie nazi recurrió al concepto de Unmensch (no humano) para justificar la «solución final» del "problema» de los judíos europeos.

Pero así como es verdad que las personas son esencialmente iguales en tanto seres individuales dotados de razón, también lo es que existen entre ellas diferencias accidentales, algunas de las cuales son superables y otras, irremediables. No tener en cuenta estos datos de la realidad 
significaría imponer una discriminación injustificada, es decir, constituiría una violación del principio de igualdad. Este último requiere en estos casos dos tipos de medidas: superación y compensación, según se trate de diferencias accidentales superables o no.

Dentro de la primera categoría figuran aquellas desigualdades a las que James Buchanan ha llamado «ambientales», es decir, aquellas que están vinculadas con la disponibilidad o la carencia de recursos económicos, culturales o políticos. Su no superación debe estar justificada y, si se admite la vigencia básica del principio de igualdad, las desigualdades estarán justificadas si y sólo si contribuyen a reducir las desigualdades accidentales superables. Esta idea está presente en la obra de John Rawls y ha sido formulada con mayor radicalidad por Carlos S. Nino $(1984,209$ ss.) con su concepción de la dependencia recíproca del grado de autonomía de los miembros de una comunidad. La no justificabilidad de las desigualdades accidentales en la sociedad capitalista constituye, como es sabido, uno de los temas centrales de los estudios de Habermas sobre la legitimidad.

En el caso de las desigualdades no superables, lo que requiere el principio de igualdad es la compensación de aquellas que constituyen un déficit de igualdad o, si se quiere, una incapacidad básica para la adopción y/o realización de planes de vida. Estas medidas pueden ser incluidas en la categoría de las disposiciones paternalistas éticamente justificables (cfr. Garzón Valdés, 1987).

Si se acepta el principio de igualdad y las consecuencias que de él se infieren, puede proponerse la siguiente definición de legitimidad:

$\mathrm{D}_{1}$

Un sistema político $S^{*}$ posee legitimidad si y sólo si respeta el principio de la igualdad esencial de todos sus miembros y procura superar y/o compensar las desigualdades accicentales de los mismos.

El procedimiento más adecuado para lograr este objetivo es el democrático pluralista, que permite el mayor grado de participación, es decir, la vigencia del principio de igualdad en el ámbito político.

Las normas o decisiones que se obtengan a través del procedimiento democrátido deben $a$ ) asegurar que no se lesione el principio de igualdad esencial, y $b$ ) promover la superación y/o compensación de las desigualdades accidentales. Dicho con otras palabras: asegurar el cumplimiento de los deberes negativos y de los deberes positivos que, en tanto tales, imponen ciertamente limitaciones al ejercicio de la autonomía individual.

La definición de legitimidad reza ahora: 
$\mathrm{D}_{2}$

Un sistema político $S^{*}$ posee legitimidad si y sólo si respeta el princípio de la igualdad esencial de todos sus miembros y procura superar y/o compensar las desigualdades accidentales a través de la imposición de deberes negativos y positivos sancionados mediante un procedimiento democrático pluralista.

Es obvio que la importancia de las diferencias accidentales entre los miembros de una comunidad política son relativas a los recursos económicos y culturales de la misma. La percepción de estas desigualdades varía según los tiempos y las sociedades. En este sentido la legitimidad es también relativa a un determinado contexto histórico-espacial. Ello explica por qué, a medida que se expande el círculo de la ética (para utilizar la conocida expresión de Peter Singer) y/o aumenta la disponibilidad de recursos (económicos, técnicos o culturales), aumenta también la clase de las desigualdades accidentales que deben ser superadas para que el sistema conserve su legitimidad. Si esto es así, puede decirse:

$\mathrm{D}_{3}$

Un sistema político $S^{*}$ posee legitimidad si y sólo si respeta el principio de la igualdad esencial de todos sus miembros y procura superar y/o compensar las desigualdades accidentales a través de la imposición de deberes negativos y positivos sancionados mediante un procedimiento democrático pluralista, de acuerdo con la disponibilidad de recursos de la respectiva sociedad.

En estas propuestas de definición de la legitimidad se hace referencia al procedimiento democrático pluralista y al principio de igualdad. Conviene formular algunas precisiones al respecto. Por lo pronto, el concepto de igualdad. ¿Igualdad en qué sentido? Ante todo, en el sentido de la igual consideración de los intereses de los miembros de una comunidad por lo que respecta a la formulación y realización de sus planes de vida. Pero igualdad también en el sentido de que todo ser humano es lo suficientemente racional como para admitir la posibilidad de distanciarse de sus propios intereses y comprender que ellos deben tener la misma relevancia cuando se trata de la formulación de normas morales. Se trata pues de una igualdad entendida tanto en sentido fáctico como normativo. Este último aspecto puede ser reformulado con el concepto de universalidad. Por cierto que alguien podría preguntar ¿por que ha de aceptarse la universalidad de las normas morales? La respuesta que considero más obvia es la siguiente: la actividad de la formulación de normas éticas, es decir, normas que ofrecen la posibilidad última de justificación de la conducta humana, está sujeta a ciertas restricciones que son las que justamente le permiten cumplir la función que de ella se espera. Por ello no es posible equiparar sin más consenso racional (tampoco en el sentido reforzado de David Gauthier) y corrección ética. No toda razón 
es una buena razón desde el punto de vista ético. Para que sea tal ha de satisfacer el requisito de poder ser aceptada (que no es lo mismo que aceptación fáctica) por todo aquel que esté dispuesto al ejercicio de su razón bajo condiciones de imparcialidad. Al respecto no existe disenso entre quienes se ocupan de cuestiones vinculadas con fundamentaciones éticas. Se puede en este sentido pensar en la formulación kantiana del imperativo categórico $o$, si se quiere buscar una fundamentación de raíz empírica, recordar a Hume:

La noción de la moral implica algún sentimiento común a toda la humanidad, que recomienda el mismo objeto a la aprobación general y hace que todo hombre, o la mayoría de los hombres, coincidan en la misma opinión o decisión al respecto. Implica también algún sentimiento tan amplio como para poder ser extendido a toda la humanidad y hacer que las acciones y la conducta, hasta de las personas más remotas, sean objeto de aplauso o de censura, según que coincidan o no con la regla acerca de lo que es correcto que se ha establecido $[1957,93]$.

$Y$ a quien siguiera aduciendo que el principio de universalidad de las normas éticas no le convence podría respondérsele que su argumento es similar al de quien sostiene que no le convence la exigencia de falsabilidad que rige para las leyes de la ciencia empírica.

Justamente este criterio de la universalidad de los principios éticos es relevante también con respecto a las limitaciones de la democracia representativa y pluralista. Quienes como Buchanan insisten en la importancia del consenso lo hacen porque temen - con no poca razónque las decisiones mayoritarias puedan poner en peligro el respeto a la autonomía individual de las personas. Ya Kelsen había señalado la necesidad de distinguir entre el "principio de la mayoría" y el "dominio de la mayoría» $(1925,31)$. Aquél exige el respeto a la autonomía de la minoría como un derecho que no puede ser objeto de negociación parlamentaria. Este derecho constituye el núcleo del sistema parlamentario: lo que podría llamarse el «coto vedado» de lo no negociable.

También en los sistemas políticos que poseen legitimidad existe un "coto vedado" integrado por aquellos derechos derivados del principio de igualdad básica y de la superación y/o compensación de las desigualdades accidentales. El respeto de este "coto vedado", es decir, del goce de los derechos en él incluidos a través de la vigencia de deberes negativos y positivos, es lo que confiere homogeneidad básica a la sociedad, a la vez que impone limitaciones a las decisiones gubernamentales, siendo aquí irrelevante el que aquéllas cuenten con el consentimiento o no de los gobernados. Homogeneidad en este sentido no significa nivelación de la posibilidad de satisfacción de todo tipo de deseos e intereses sino tan 
sólo de aquellos que podrían ser llamados «primarios» y, en tanto tales, están caracterizados por su universabilidad. Que el grado de satisfacción está vinculado con la disponibilidad de recursos es obvio si se recuerda que todo deber ser o hacer presupone el poder ser o hacer. Otra es, en cambio, la situación con respecto a la validez ética de las reglas que regulan la satisfacción de los deseos e intereses secundarios (o particulares, si se quiere utilizar la designación habermasiana) de los miembros de la sociedad. Esta validez sí depende de la aceptación fáctica de sus destinatarios. Para este ámbito valen las consideraciones de Fishkin sobre la cultura política autorreflexiva.

Si se acepta esta definición de homogeneidad social básica y la relevancia de la aceptación fáctica de las reglas que regulan la satisfacción de los deseos e intereses secundarios de los miembros de una comunidad política, podría ahora sugerirse la siguiente definición de legitimidad:

$\mathrm{D}_{4}$

Un sistema político $\mathrm{S}^{*}$ posee legitimidad si y sólo si asegura la homogeneidad social básica, y las reglas que regulan la satisfacción de los intereses secundarios de sus miembros cuentan con la aceptación fáctica de sus destinatarios, expresada a través de un procedimiento democrático pluralista.

A esta definición -como a las anteriores - alguien podría objetar que la referencia al procedimiento mediante el cual se expresa la aceptación de las reglas que regulan la satisfacción de los intereses secundarios es, en el mejor de los casos, innecesaria y, en el peor, peligrosa. Innecesaria porque es irrelevante el procedimiento si lo que importa es el resultado; peligrosa porque puede encubrir un eurocentrismo que destruya vías ya probadas y eficaces para la promulgación de estas reglas: si todos o la mayoría están satisfechos con la forma como se regulan sus deseos secundarios, ¿por qué exigir la aplicación de un único procedimiento?

Estas dos objeciones, en el fondo, apuntan a una demanda de justificación de la democracia pluralista. No he de entrar aquí en el tratamiento de este problema. Deseo tan sólo formular algunas aseveraciones: $a$ ) la democracia pluralista es la mejor forma de asegurar la igualdad política, al permitir y estimular la participación de todos los ciudadanos; $b$ ) el ejercicio de la democracia pluralista es la vía más adecuada para garantizar el desarrollo a nivel político de la autonomía individual (es decir, de la racionalidad en sentido fuerte) y evitar - dentro de lo posible- el peligro de la manipulación paternalista y de la adopción apática de normas de conducta; y c) la aceptación de los resultados obtenidos por esta vía es la expresión más realista del grado máximo de consenso que puede lograrse en un momento dado con respecto a una decisión colectiva. 
De esta manera, vuelvo al comienzo e incorporo en la definición de legitimidad los elementos del consenso y de la racionalidad "filtrados» ahora por los requisitos de la homogeneidad social y de la satisfacción democrático-pluralista de los intereses secundarios de las personas. La ubicación de estos dos elementos es, por otra parte, diferente a la de los seis casos mencionados: el consenso y la racionalidad no aparecen en la génesis de la legitimidad de un sistema político (ya que ella puede ser impuesta heterónomamente y no con el propósito de satisfacer preferencias unánime o mayoritariamente compartidas sino justamente de transformarlas); son datos que deben ser tomados en cuenta en la definición de la legitimidad: la racionalidad como elemento esencial de la igualdad básica de las personas y el consenso fáctico restringido a las normas que regulan los compromisos que los miembros de una sociedad pueden llevar a cabo fuera del ámbito no negociable del "coto vedado".

\section{BIBLIOGRAFIA}

Buchanan, James M.: The Limits of Liberty, Chicago/Londres, 1975.

ELSTER, John: Sout Grapes - Studies in the subversion of rationality, Cambridge, 1983.

FISHKIN, James S: "Bargaining. Justice and Justification", Social Philosophy \& Policy, 5, 2 (1988), $46 \mathrm{ss}$.

GARZON VALdes, Emesto: "¿Es éticamente justificable el paternalismo jurídico?", Revista Latinoanericana de Filosofía (Buenos Aires), XIII, 3 (1987).

Gauthler, David: Morals by Agreement, Oxford. 1986.

GINÉS DE SEPÚLVEdA, Juan: Tratado sobre las justas causas de la guerra contra los indios, México, 1941.

HABERMAS, Jürgen: Moralbewtißtsein und komunikatives Handeln, Francfort, 1983.

Kelsen, Hans: Das Problem des Parlamentarismus, Viena/Leipzig, 1925.

LliHMANN, Niklas: Legitimation durch Verfahren, Darmstadt/Neuwied, 1970.

Nino, Carlos S.: Ética y derechos humanos, Buenos Aires, 1984.

Rawis, John: A Theory of Justice, Cambridge, Mass, 1971.

HuME, David: An Inquiry concenzing the Principles of Morals, Indianápolis/Nueva York, 1957. 